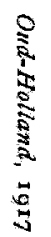
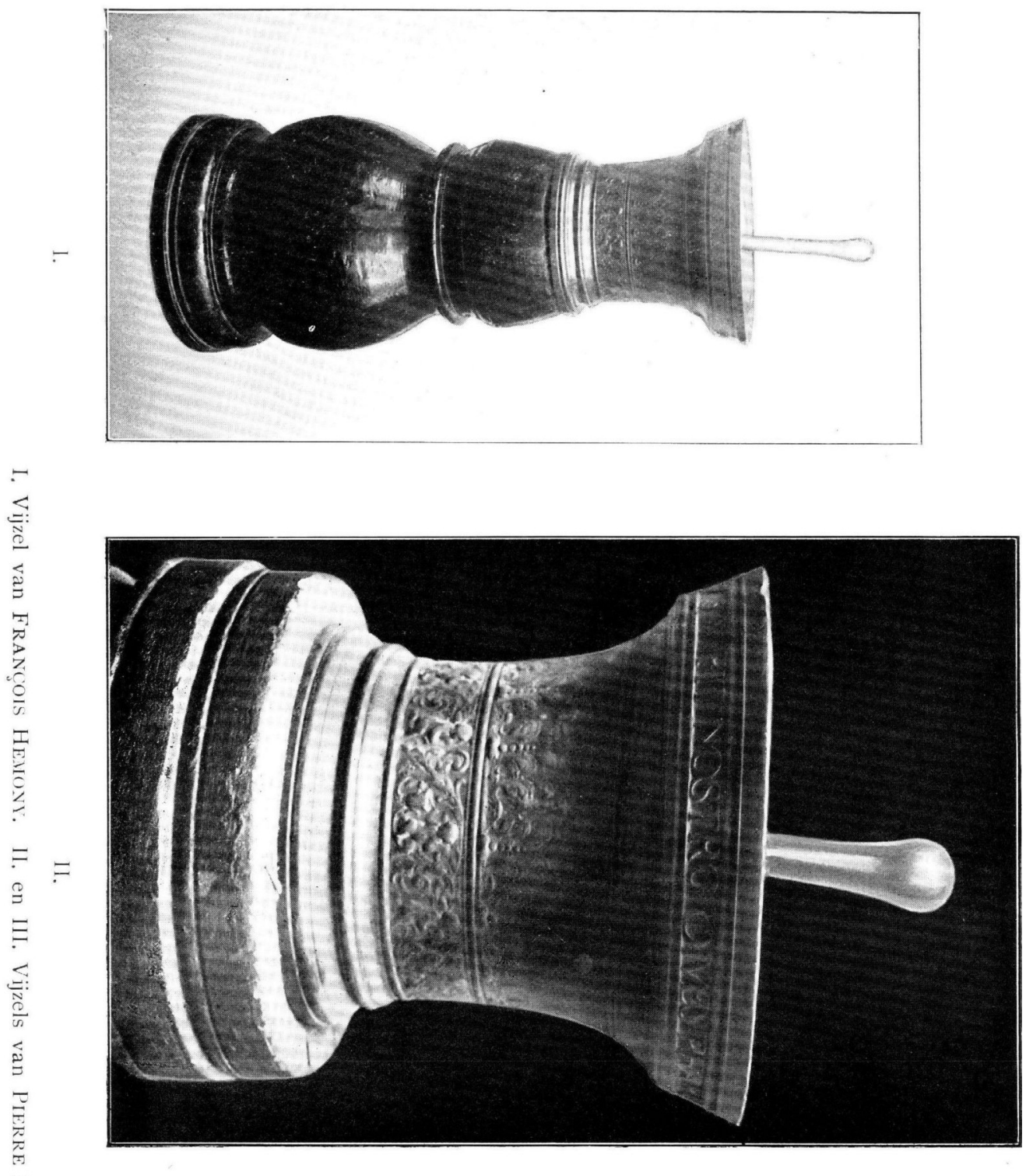

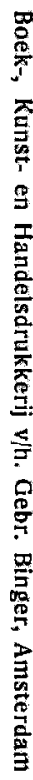

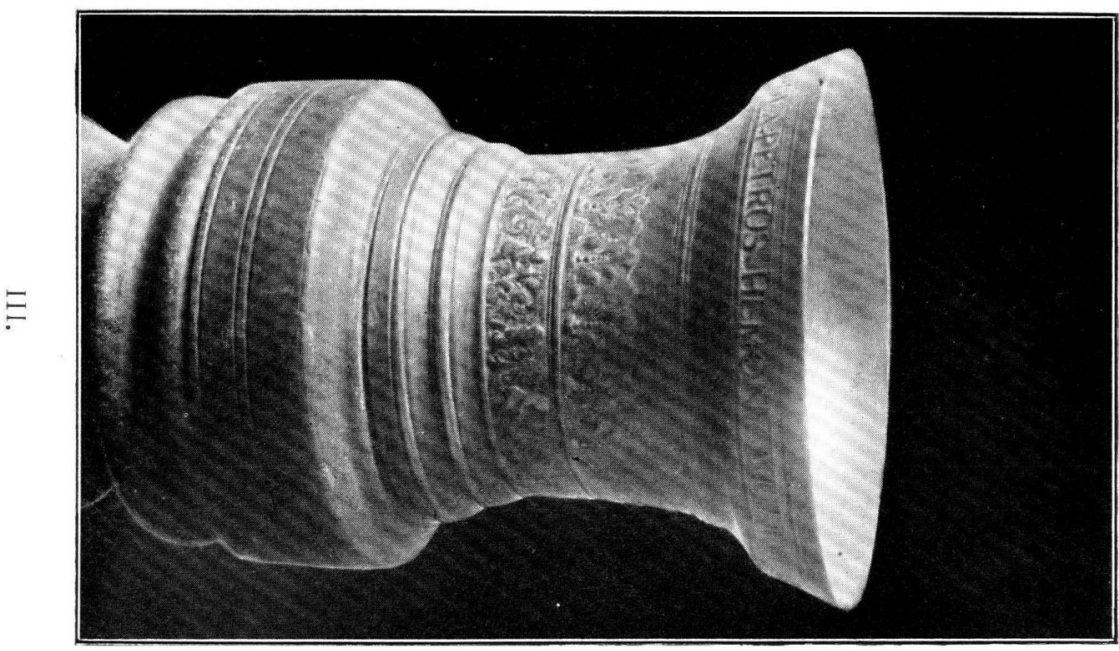




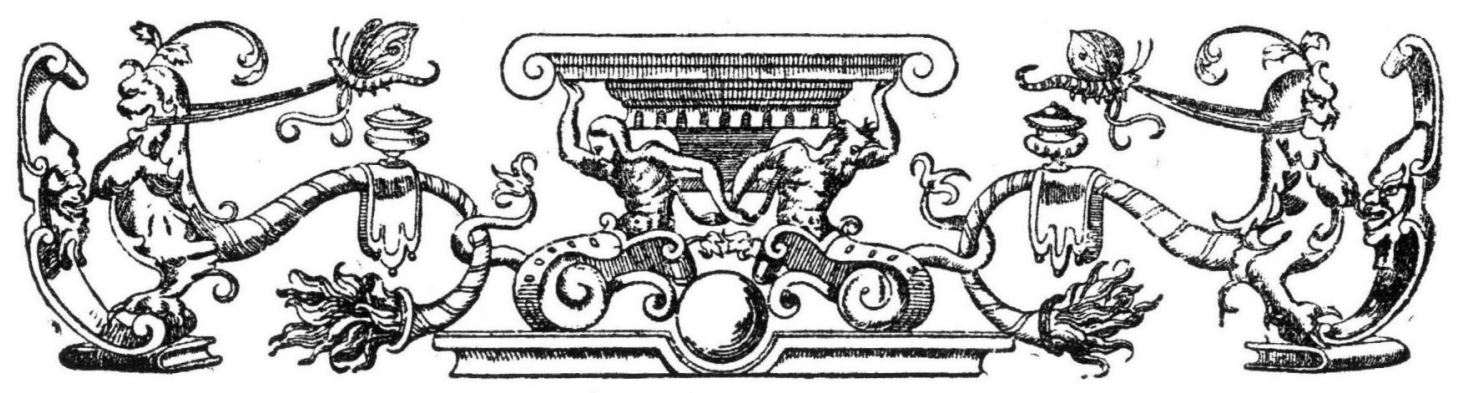

\title{
De Vijzels van François en Pierre Hemony
}

DOOR

\author{
L A URA SA LM.
}

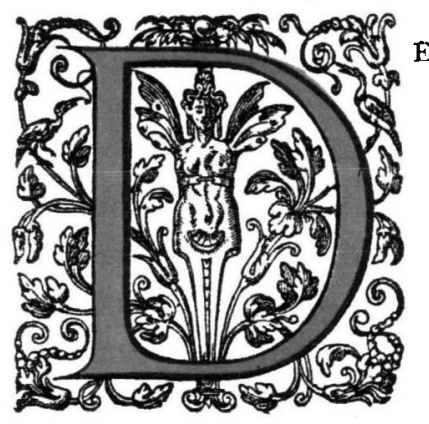

E wereldberoemde klokkengieters FrançOIS en PIERRE HEMONY hebben niet alleen klokken gegoten, doch hebben ook nog andere kunstvoorwerpen vervaardigd, die, hoewel minder bekend, toch de moeite loonen er de aandacht op te vestigen.

Waarschijnlijk zijn de gebroeders HEMONY door den 30-jarigen oorlog, waarin verschillende landen van Europa gewikkeld waren, gevlucht naar Duitschland, waar zij zich bekwaamden in het metaalgietersvak, dat zij later in onze Republiek uitoefenden.

François Hemony werd geboren in het jaar 1609 en zijn broeder PierRe tien jaren later, beiden te Levécourt, een klein plaatsje in Fransch Lotharingen. "Levécourt is een plaatsje in het tegenwoordige Fransche departement van de Haute-Marne, aan den rechteroever van de Maas, tusschen Bourmont en Clefmont. Daar had BLAISE HEMONIN, denkelijk wel de vader van François en Pierre HEMONY, eene klokgieterij, zegt J. W. ENSCHEDE 1), die hiervoor verwijst

1) G. D. BoM H. Gz. De Zuiderkerk te Amsterdarn met twee bijdragen, over het orgel en de klokken. door J. W. ENSCHEDk, Amsterdam IgI , bl. 66.

Oud-Holland, I917. 
naar eene studie van JOSEPH BERTHELÉ over „Les fondeurs de cloches de la Sénechaussée de Bourmont du XVIe au XVIIIe siècle, d'après les recherches de M. Jules Marchal", opgenomen in de Revue de l'art chrétien IV (1893), livraison 2. FRANÇOIS vestigde zich in 1642 met zijn broeder PIERRE te Zutphen, waar hij in 1644 voor den Wijnhuistoren aldaar zijn eerste klokkenspel maakte. Den Ioden December $1655^{1}$ ) werd FRANÇOIS HEMONY in Amsterdam als stadsklok- en geschutgieter aangesteld, en werd hem tot werkplaats aangewezen de plaats waar het tegenwoordige pakhuis „'t Scheepje"2) staat op de Keizersgracht hoek Molenpad, waar hij zich een jaar later vestigde. Toen FRANÇOIS HEMONy in 1667 was overleden werd tot zijn opvolger als stadsklok- en geschutgieter zijn broeder PIERRE aangesteld. In dien tijd en later bestond er nog een tweede geschut- en klokgieterij te Amsterdam in een nu nog bestaand perceel, het gebouw "De Weichsel" in de Gieterstraat hoek Lijnbaansgracht. WAGENAAR noemt het in dl. 2, bl. 46: Karthuizers-straat; maar in de Bijvoegsels en Verbeteringen van dl. 3 zegt hij : "Karthuizers-straat, lees Karthuizers- of Gieters-straat”. Zoo blijft nog de herinnering aan de gieterij in den straatnaam bewaard. In het jaar 1676 werd PIERRE ziek, stierf den 17 den Februari 1680 , en werd den 22 sten Februari begraven op het koor van de Nieuwe Kerk te Amsterdam ${ }^{3}$ ). In Oud-Holland lezen wij: „De HeMony's goten, zooals bekend is, niet uitsluitend klokken. Dit was reeds te Zutphen het geval, waar FRANÇOIS in 1653 betaling erlangt voor een koperen gewicht, een nieuwe bus en een schijf voor de kraan, alsook voor tien metalen pannen ten behoeve der watermolens" 4).

In 1662 leverde FRANÇOIS de koperen speelton met speelschroeven, volgens de uitvinding van den Nijmeegschen uurwerkmaker JAN CAL 3 ). Van I $66_{3}$ tot $166_{5}$ goot FrançoIs "de door QUELlinus zoo meesterlijk gemodelleerde beelden: de Voorzichtigheid, de Matigheid, de Wakkerheid, de Rechtvaardigheid, den Vrede en den Atlas met den Wereldkloot"6), die nog het sieraad uitmaken van het tegenwoordige Paleis op den Dam, terwijl men in het Museum der Vereeniging Oud Dordrecht een scheepsklok aantreft door F. HEMONy gegoten. Deze luiklok is $\pm 35 \mathrm{cM}$. hoog en $32 \mathrm{cM}$. in grootste doorsnee. Boven het randschrift, luidende "Franciscus HEMony me fecit Amstelodam A $\mathrm{A}^{\circ}$ 1660", is aangebracht een rand, versierd met engelties; er onder een randversiering van engelenkopjes.

\footnotetext{
1) t. a. p. bi. 67 .

2) Dr. P. Scheltema, Aemstels Oudheid, De stads-klokgieters en klokgieterijen, Amsterdam r872, bl. 137.

3) Dr. H. C. ROGgr, De Klokkengieters Frasçors en PIERrE Hemony; in het Amsterdamscb Jaarboekje 1898, bl. 63 .

4) J. GiMberG in Oud-Holland X (t892), bl. 23.

§) Dr. H. C. RogGe, t. a. p. bl. 55 .

o) Dr. H. C. RogGe, t. a. p. bl. 5 t.
} 
Ten laatste wijs ik nog op de, door HEMONY uit klokspijs gegoten, langwerpig vierkante staafjes, oorspronkelijk dienende bij het op toon brengen der klokken. "Heel net wist hij ook die op heelen en halve toonen te brengen, en deze staafkens kan men brengen 't zij op bruylotten of andere gezelschappen in een kamer waar men begeerde; zij worden nevens elkander geleydt gelijk de klavieren van een klavecymbaal, daar men met twee houte stokskens, hier toe gemaakt, kan opspeelen, en maken zulk een zoet en helder geluyt oft kleyne klokskens waren, dat vermaaklijk is om aan te hooren; deze kunst was nieuw, en van niemand als van deze Monsieur Hemony, voor dezen gevonden" ').

Minder bekend is het, dat er ook vijzels door de beide broeders FrançoIs en Pierre Hemony gegoten werden. Vroeger werden de vijzels over't algemeen meer gebruikt dan tegenwoordig. Toenmaals moest iedere apotheker met eigen krachten de kruiden stampen en bewerken; nu daarentegen ondergaan de kruiden in den pharmaceutischen groothandel hun verschillende bewerkingen, en iedere apotheker kan de gewenschte kruiden gereed voor gebruik laten komen. Het spreekt dus vanzelf dat er in dien tijd veel vijzels noodig waren, welke men zich ook gemakkelijk zonder te groote kosten kon aanschaffen, omdat de koperwaarde bij den tegenwoordigen tijd vergeleken gering was.

Wel bestaan er nog vele oudere vijzels dan die der gebroeders HEMONy, doch geen dier vijzels is zoo fijn bewerkt, met zooveel smaak versierd, als de vijzels van François en Pierre Hemony. Veel Hemony-vijzels zijn er echter niet meer te vinden. Waarschijnlijk zijn de meeste naar Engeland gegaan, doch ook in ons land zijn er enkele overgebleven, die ik door de welwillendheid der eigenaars heb mogen laten photografeeren.

De oudste dezer Hemony-vijzels bevindt zich te Amersfoort in de Apotheek van den Heer D. H. G. ItTMANN (Firma v. D. ZOO DE JONG), Langestraat 9 (Afb. I). De hoogte is 28 c.M., de breedte in doorsnee bedraagt van boven 35 c.M., van onderen 23 c.M. De vijzel heeft een omvang van boven gemeten I I c.M., in 't midden 70 c.M. en van onderen 82 c.M., terwijl het gewicht van dien vijzel 52 K.G. bedraagt. Het omschrift is als volgt:

Campanae mortem resonant Mortaria morbos. F. HEMONy me fecit $A^{0}$ i $66 \mathrm{I}$.

De randversiering onderaan wordt gevormd door mollige engeltjes, muziekinstrumenten bespelend: klokjes, bekkens, harp, triangel en zelfs een vijzel met één of twee stampers. Boven is een rand van acanthus-bladen aangebracht; beide randen zijn elk 5 cM. breed.

In het Laboratorium van het Wilhelmina-Gasthuis, iste Helmersstraat te

1) Casparus Commelin, Beschrijving van Amsterdam enz. t'Amsterdam 1694, bl, $44^{2}$. 
Amsterdam, kan men een fraaien oud bronzen vijzel vinden door Petrus Hemony in het jaar 1675 gegoten. (Afb. II). Staande op zijn houten voetstuk, elegant van model, smaakvol met kunstig bewerkte randen versierd, voldoet hij nog steeds aan het doel waarvoor hij nu bijna twee en een halve eeuw geleden gegoten werd. Het omschrift van dezen vijzel luidt als volgt:

Fit nostro dives pharmacopola sono.

Petrus Hemony me fecit $\mathrm{A}^{0} \mathbf{} 675$.

Ook de Heer M. HofstE, apotheker te Amsterdam, Prinsengracht 7 I2, voorheen Nieuwenhuis en Stoeder, is eigenaar van een Hemony vijzel (Afb. III). Deze vijzel, overigens geheel overeenkomende met den vijzel van het WilhelminaGasthuis, draagt het volgende omschrift:

Fit nostro dives pharmacopola 1).

Petrus Hemony me fecit Amstelodami Ao 1675.

Van één vijzel heb ik alleen een vermelding gevonden, n.l. in „Het Boek der Opschriften" van Mr. J. VAN LENNEP en J. TER GoUw 2). Daar lezen wij dat deze vijzel, toen eigendom van den Heer F. KRIJZER, tot randschrift heeft:

Si Deus pro nobis quis contra nos.

F. 3) Hemony me fecit Amstel. 1675.

VAN LENNEP en TER GOUW voegen daaraan toe: "Zeker waren zijn vijzels ook zoo konstrijck toegegoten, dat zelfs het stampen iets van een volks-of liever keuken-concert had, en 't gehoor verleckren kon" 4).

Bij nasporing is mij gebleken dat de Heer F. KRIJZER, die oudtijds woonde in de Weste Wagenstraat te Rotterdam, antiquaar was; bij zijn overlijden zijn al de antieke schatten uit zijn magazijn verkocht, en zoo zal ook de oude koperen HEMONY-vijzel uit 't oog verloren zijn gegaan, want bij opsporingen naar bovengenoemden vijzel te Rotterdam heb ik niet kunnen vernemen waar hij gebleven is.

Het is mij niet mogen gelukken meer HEMONY-vijzels op te sporen, want ook in de voornaamste Musea van Oudheden 5 ) in ons land komen geen HEMONYvijzels voor.

1) Opmerkelijk is het dat het woord "sono" hierbij ontbreekt.

2) Mr. J. VAN Lennep en J. TER Gouw. Het Boek der Opschriften, Amsterdam 1869, bl. 328.

3) Waarschijnijk is de $F$. een drukfout voor $P$, daar de volgende zin ook over PIETER vervolgt en Frakçors in 1675 reeds overleden was.

4) Vgl. Vondel "Op het klokmusyk t' Amsterdam".

5) Ik deed onderzoek bij: I Amersfoort, Museum der Vereeniging Flehité. 2 Amsterdam, Geschiedkundig medisch-pharmaceutisch Museum in het Stedelijk Museum. 3 Amsterdam, Rijksmuseum. 4 Assen, Museum van Oudheden in Drenthe. 5 Delft, Rijksmuseum, Huis Lambert van MeErTen. 6 Dordrecht, Museum der Vereeniging „Oud Dordrecht". 7 Edam, Museum te Edam. 8 Groningen, Museum van Oudheden. 9 Haarlem, Frans Hals Museum. Io Haarlem, Museum van Kunstnijverheid. II Haarlem, Museum Van Stolk. 12 Hoorn, West-Friesch Museum. 13 Leeuwarden, Friesch Genootschap van Geschied-Oudheid-en Taalkunde, 14 Middelburg, Zeeuwsch Genootschap der Wetenschappen. 15 Rotterdam, Museum van Oudheden. 16 Zaandijk, Zaanlandsche Oudheidkundige Verecniging. 
De HEMONY-vijzels komen allen, wat gewicht, grootte en omvang betreft, vrijwel met elkaar overeen. Ook den engelenrand en den rand met acanthusbladen vindt men op elken door mij gevonden vijzel terug, terwijl het omschrift meestal verschillend is. Dezelfde onderste randen, namelijk den engelenrand met den rand van acanthusbladen, vindt men eveneens op een door FRANÇOIS HEMONY gegoten klok. Deze dubbele rand staat afgebeeld in "De Torenmuziek in de Nederlanden" naar een gips-afgietsel 1) van die klok in het Rijksmuseum te Amsterdam.

De vijzels staan ook ieder op een houten voetstuk (Afb. V), bestaande uit twee op elkaar in grootte verschillende bollen of wel uit één grooten bol. Daarboven zijn twee schijven. Hierop staat de vijzel, terwijl onder den grootsten bol afloopende breedere randen gemaakt zijn, waar het geheel op rust. Iedere vijzel heeft bovendien nog een ijzeren stamper, waarvan boven- en onderkant een weinig breed uitloopen, zoodat men dien, hem in 't midden vasthoudend, gemakkelijk hanteeren kan. Het gewicht hiervan bedraagt ongeveer 5 Kilo.

Dat de gebroeders HEMONY ook bij het gieten van vijzels gezorgd hebben een zuiveren toon te voorschijn te roepen, blijkt niet alleen uit den zuiveren klank dien elke HEMONY-vijzel heeft, maar ook hieruit, dat zij in het randschrift nadruk gelegd hebben op den klank, zij hadden immers nun roem te danken juist aan hun muzikaal talent. In het vlugschriftje over: De onnoodzakelijkheid en ondienstigheid van $C$ is en Dis in de bassen der klokken, bijeenverzameld door PETRus HEMONY "uyt verscheydene advyzen van ervaren organisten ende klokkenspeelders, (Delft 1678 ) schrijft D. Scholl de volgende woorden:

nDen intrest van het Capitaal

Dat is 't geluyt van dat metaal".

't Is niet te verwonderen dat de klokkengieters ook vijzels goten, omdat die bijna denzelfden vorm hebben als klokken. Men kan de vergelijking nog verder doorzetten: het werk dat de klepel in de klok doet, doet de stamper in den vijzel. De klank van het ijzer op het koper geeft het mooie geluid; zoo wordt ook de klokspijs uit verschillende metalen samengesteld. SchiLLER zegt in zijn Lied von der Glocke:

Denn wo das Strenge mit dem Zarten,

Wo Starkes sich und Mildes paarten,

Da gibt es einen guten Klang.

Noch dauern wird's in späten Tagen

Und ruhren vieler Menschen Ohr....

1) Mr. A. Loosjes. De Torenmuziek in de Nederlanden. Amsterdam (Igr6), tegenover bl. 4. 
Het is te hopen dat de weinige overgebleven HEMONY-vijzels nog jaren, ja eeuwen, hun schoone klanken mogen laten weerklinken, wanneer daarin voor duizenden zieken geneeskrachtige kruiden bewerkt worden; en al zijn de zuivere tonen daardoor voortgebracht niet zoo melodieus als de stemmen der HEMONYklokken, die uit de torens der kerken tot ons komen, toch hebben die klanken ook hun merkwaardige beteekenis. Immers in een zijner vijzel-opschriften, dat wij reeds in het latijn leerden kennen, vereenigt FRANÇOIS HEMONY den klank van klokken en vijzels op deze wijze:

Klokken luiden voor de dooden

Vijzels voor de zieken.

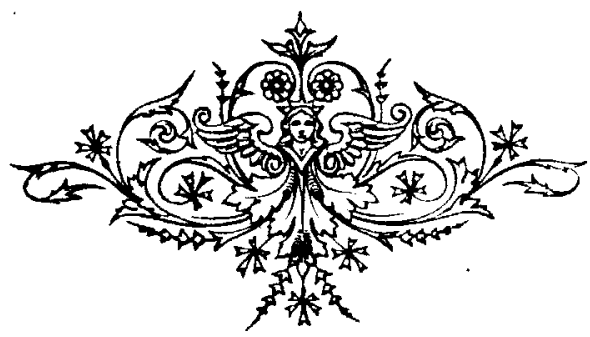

